\title{
Penerapan Metode Fuzzy Mamdani Untuk Menentukan Stok Produk Herbal Berdasarkan Permintaan dan Penjualan
}

\author{
Asyahri Hadi Nasyuha*, Masyuni Hutasuhut, Mukhlis Ramadhan \\ Prodi Sistem Informasi, STMIK Triguna Dharma, Medan, Indonesia \\ Email: ${ }^{1}$ ayi.nasyuha@gmail.com
}

\begin{abstract}
Abstrak
Penjualan merupakan salah satu kegiatan yang banyak dilakoni masyarakat sebagai bidang usaha yang menjanjikan. Prediksi jumlah barang yang akan dijual harus sesuai dengan stok pada toko agar permintaan dan penjualan dapat terpenuhi. Oleh karena itu, diperlukan suatu sistem untuk mengetahui jumlah stok produk herbal agar tidak mengalami permasalahan dalam menentukan stok di setiap bulannya. Dengan menggunakan metode Fuzzy Mamdani sebagai algoritma penyelesaian masalahnya, dan kriteria yang diubah dalam bentuk bobot penilaian sehingga sistem dapat melakukan perhitungan yang memberikan kecepatan informasi dalam bentuk sistem yang terkomputerisasi. Hasil penelitian ini bertujuan untuk menerapkan metode logika fuzzy Mamdani dalam memprediksi jumlah stok produk herbal berdasarkan data penjualan dan jumlah permintaan. Memberikan hasil berupa informasi yang di cetak dalam bentuk laporan yang berisi data pemesanan untuk jumlah pemesanan stok berikutnya.
\end{abstract}

Kata Kunci: Penentuan Stok Produk Herbal, Fuzzy Mamdani

\section{Abstract}

Sales is one of the activities undertaken by many people as a promising business field. Prediction of the number of items to be sold must be in accordance with stock at the store so that demand and sales can be fulfilled. Therefore, we need a system to find out the amount of stock of herbal products so they do not experience problems in determining stock in each month. By using the Fuzzy Mamdani method as an algorithm for solving the problem, and the criteria are changed in the form of weighting so that the system can do calculations that provide the speed of information in the form of a computerized system. The results of this study aim to apply the Mamdani fuzzy logic method in predicting the amount of herbal product stock based on sales data and the number of requests. Provides results in the form of information printed in a report containing order data for the number of subsequent stock orders.

Keywords: Determination of the Stock of Herbal Products, Fuzzy Mamdani

\section{PENDAHULUAN}

Produk herbal semakin banyak dimintai oleh masyarakat karena dapat dipercaya membantu kesehatan masyarakat dengan penggunaan bahan yang lebih sehat karena berasal dari tumbuhan. Produk herbal ini ada beberapa jenis mulai dari obat-obatan, suplemen makanan sampai dengan kosmetik, hingga sudah tidak asing lagi bagi sebagian penduduk Indonesia terutama yang beragama Islam. Kegiatan pengelolaan stok produk herbal setiap bulannya terus berlangsung, bahkan pengelolaan stok dilakukan setiap harinya sehingga dengan berkurangnya stok produk khususnya pada produk jenis Sabun Transparan Kolagen yang sangat diminati, tentunya mendatangkan kesulitan tersendiri bagi tenaga kerja dalam melakukan kegiatan transaksi dan membuat laporan, karena dalam pengerjaannya selama ini masih dikelola secara manual. Agar pengelolaan stok produk herbal dapat terkelola dan tertata dengan baik, maka perlu dikembangkan suatu aplikasi .Sistem Informasi Manajemen Stok Produk Herbal ini akan menampung semua data pembelian, penjualan serta permintaan dari agen, dan para konsumen. Permasalahan yangterjadi selama ini adalah untuk mengetahui jumlah pemesanan produk yang akan dipesan harus mengecek satu persatu produk yang masih tersisa dan dengan menjumlahkan data permintaan, penjualan serta stok. Proses pengerjaan laporan ini tentu saja memakan waktu sehingga dibutuhkan waktu yang lama dalam melakukan pemesanan dan menyebabkan adanya kekosongan stok pada toko dan produk yang kurang diminati menjadi lama terjual, hal ini mengakibatkan pihak menejemen kesulitan sehingga proses penjualan terganggu dan mengakibatkan perusahaan mengalami kerugian. Berdasarkan masalah yang terjadi, dibutuhkan sistem baru yang lebih mendukung dalam menyelesaikan transaksi untuk mengetahui jumlah stok produk herbal agar tidak mengalami permasalahan dalam stok penjualan. Salah satu cara yang bisa digunakan dalam menentukan jumlah stok produk adalah penerapan logika fuzzy Mamdani, karena terdapat beberapa data yang bisa digunakan dalam melakukan perhitungan guna mendapatkan jumlah stok produk herbal.

\section{TEORITIS}

\subsection{Sabun Herbal}

Produk sabun mandi telah berkembang menjadi kebutuhan primer diseluruh lapisan masyarakat. Sabun dapat digunakan untuk mengobati penyakit, seperti mengobati penyakit kulit yang disebabkan oleh bakteri dan jamur. Dengan kata lain sabun dapat digunakan sebagai obat yaitu dengan membersihkan tubuh sehingga kemungkinan terserang penyakit akan berkurang. Kelebihan sabun herbal jika dibandingkan dengan sabun yang lain, sabun 
herbal ini mudah dibawa, mudah disimpan, memilika banyak khasiat dan manfaat, dan penampilan kemasan yang eksklusif.

\subsection{Teori Permintaan}

Hendratno (2008) dalam Pontoh, Palar \& Mauna. (2016). Permintaan dan Penawaran Beras di Indonesia(Pada Tahun 2003-Tahun 2013). Jurnal Berkala Ilmiah Efisiensi Vol. 16(04), 836. Menjabarkan bahwa teori permintaan konsumen ini didasarkan pada teori periaku konsumen (consumer behavior), dimana menunjukkan perilaku konsumen dalam menentukan konsumsi barang. Sedangkan permintaan sendiri merupakan keinginan konsumen untuk membeli suatu barang pada berbagai tingkat harga selama periode waktu tertentu. Fungsi permintaan adalah persamaan yang menunjukkan hubungan antara permintaan barang dan jasa dengan faktor-faktor yang mempengaruhinya. Permintaan sendiri adalah jumlah barang/jasa yang ingin diminta oleh konsumen pada berbagai tingkatan harga selama periode waktu tertentu.

\subsection{Logika Fuzzy}

Logika fuzzy merupakan salah satu komponen pembentuk soft computing. Logika fuzzy pertama kali diperkenalkan oleh Prof.Lofti A.Zadeh pada tahun 1965. Dasar logika fuzzy adalah teori himpunan fuzzy. Pada teori himpunan fuzzy, peranan derajat keanggotaan sebagai penentu keberadaan elemen dalam suatu himpunan sangatlah penting. Nilai keanggotaan atau derajat keanggotaan atau membership function menjadi ciri utama dari penalaran dengan logika fuzzy tersebut. (Sri Kusumadewi \& Purnomo,2013: 1).

\subsection{Metode Mamdani}

Sri Kusuma Dewi \& Purnomo (2013). Metode Mamdanidikenal sebagai metodeMax-Min. Metode ini diperkenalkanoleh Ebrahim H. Mamdani pada tahun 1975. Untukmendapatkan output (hasil), diperlukan 4 tahapan:

1. Pembentukan himpunan fuzzy, Pada metode Mamdani, baik variable input maupun variabel outputdibagi menjadi satu atau lebih himpunan fuzzy.

2. Aplikasi fungsi implikasi, Pada tahapan ini, disusun basis aturan, yaituaturan-aturan berupa implikasi-implikasi fuzzyyang menyatakan relasi antara variabel inputdengan variabel output. Pada MetodeMamdani, fungsi implikasi yang digunakanadalah Min.

3. Komposisi aturan, Tidak seperti penalaran monoton, apabila sistem terdiri dari beberapa aturan,maka inferensi diperoleh dari kumpulan dankorelasi antar aturan. Ada 3 metode yangdigunakan dalam melakukan inferensi systemfuzzy, yaitu:

a. Metode Max (Maximum)Pada metode ini, solusi himpunan fuzzydiperoleh dengan cara mengambil nilaimaksimum aturan, kemudian menggunakannilai tersebut untuk memodifikasi daerahfuzzy dan mengaplikasikannya ke outputdengan menggunakan operator OR(gabungan). Jika semua proporsi telahdievaluasi, maka outputakan berisi suatuhimpunan fuzzy yang merefleksikankontribusi dari tiap-tiap proporsi. Secaraumum dapat dituliskan:

$$
\mu_{\mathrm{sf}}\left(\mathrm{x}_{\mathrm{i}}\right)=\max \left(\mu_{\mathrm{sf}}\left(\mathrm{x}_{\mathrm{i}}\right), \mu_{\mathrm{kf}}\left(\mathrm{x}_{\mathrm{i}}\right)\right.
$$

dengan,

$\mu_{\mathrm{sf}}\left(\mathrm{x}_{\mathrm{i}}\right)=$ nilai keanggotaan solusi fuzzysampai aturan ke-i

$\mu_{\mathrm{kf}}\left(\mathrm{x}_{\mathrm{i}}\right)=$ nilai keanggotaan konsekuenfuzzy aturan ke-i

b. Metode Additive (Sum)Pada metode ini, solusi himpunan fuzzydiperoleh dengan cara melakukanpenjumlahan terhadap semua output daerahfuzzy.Secaraumum dapat dituliskan:

$$
\mu_{\mathrm{sf}}\left(\mathrm{x}_{\mathrm{i}}\right)=\min \left(1, \mu_{\mathrm{sf}}\left(\mathrm{x}_{\mathrm{i}}\right) .+\mu_{\mathrm{kf}}(\mathrm{xi})\right)
$$

dengan,

$\mu_{\mathrm{sf}}\left(\mathrm{x}_{\mathrm{i}}\right)=$ nilai keanggotaan solusi fuzzysampai aturan ke-i

$\mu_{\mathrm{kf}}\left(\mathrm{x}_{\mathrm{i}}\right)=$ nilai keanggotaan konsekuenf $u z z y$ aturan ke-i

c. Metode Probabilistik (probar)Pada metode ini, solusi himpunan fuzzydiperoleh dengan cara melakukan perkalianterhadap semua output daerah fuzzy.Secaraumum dapat dituliskan:

$\mu_{\mathrm{sf}}\left(\mathrm{x}_{\mathrm{i}}\right)=\left(\mu_{\mathrm{sf}}\left(\mathrm{x}_{\mathrm{i}}\right)++\mu_{\mathrm{kf}}\left(\mathrm{x}_{\mathrm{i}}\right)\right)-\left(\mu_{\mathrm{sf}}\left(\mathrm{x}_{\mathrm{i}}\right) \cdot{ }^{*} \mu_{\mathrm{kf}}\left(\mathrm{x}_{\mathrm{i}}\right)\right)$

dengan,

$\mu_{\mathrm{sf}}\left(\mathrm{x}_{\mathrm{i}}\right)=$ nilai keanggotaan solusi fuzzysampai aturan ke-i

$\mu_{\mathrm{kf}}\left(\mathrm{x}_{\mathrm{i}}\right)=$ nilai keanggotaan konsekuenfuzzy aturan ke-i

4. Defuzzifikasi (Penegasan)

Input dari proses penegasan adalah suatuhimpunan fuzzy yang diperoleh dari komposisiaturan-aturan fuzzy, sedangkan output yangdihasilkan merupakan suatu bilangan real yangtegas. Dengan demikian jika diberikan suatuhimpunan fuzzy dalam range tertentu, makaharus dapat diambil suatu nilai tegas tertentusebagai output. 
Ada beberapa cara metode penegasan yangbiasa dipakai pada komposisi aturan Mamdani yang dapat digunakan, antara lain:

a. Metode Centroid(Composite Moment)

Pada metode ini, solusi himpunan tegas (crips) di peroleh dengan cara mengambil titik pusat ( $\mathrm{z}^{*}$ ) daerah fuzzy. Secara umum dirumuskan:

$$
\begin{array}{lr}
\mathrm{Z} *=\frac{\int_{\mathrm{z}} z \mu(z) d z}{\int_{\mathrm{Z}} \mu(z) d z} & \text { untuk variabel kontinu,atau } \\
\mathrm{Z} *=\frac{\sum_{j=1}^{n} z j \mu(z j)}{\sum_{j=1}^{n} \mu(z j)} & \text { untuk variabel diskret. }
\end{array}
$$

b. Metode Bisektor

Pada metode ini, solusi himpunan tegas (crips) diperoleh dengan cara mengambil nilai pada domain fuzzy yang memiliki nilai keanggotaan setengah dari jumlah total nilai keanggotaan pada daerah fuzzy. Secara umum dituliskan:

$$
\text { Z } p \text { Sedemikian hingga } \int_{R 1}^{p} \mu(z) d z=\int_{p}^{R n} \mu(z) d z
$$

c. Metode Mean of Maximum (MOM)

Pada metode ini, solusi himpunan tegas (crips) diperoleh dengan cara mengambil nilai rata-rata domain yang memiliki nilai keanggotaan maksimum.

d. Metode Largest of Maximum (LOM)

Pada metode ini, solusi himpunan tegas (crips) diperoleh dengan cara mengambil nilai terbesar dari domain yang memiliki nilai ke anggotaan maksimum.

e. Metode Smallest of Maximum (SOM)

Pada metode ini, solusi himpunan tegas (crips) diperoleh dengan cara mengambil nilai terkecil dari domain yang memiliki nilai ke anggotaan maksimum.

\subsection{Pemodelan Sistem}

Pemodelan Sistem adalah suatu bentuk penyederhanaan dari sebuah elemen dan komponen yang sangat komplek untuk memudahkan pemahaman dari informasi yang dibutuhkan. Pada penelitian ini akan dibutuhkan sebuah pemodelan sistem yang akan menerapkan metode yang digunakan, tujuannya ialah sistem yang dibangun sudah memiliki rancangan yang sesuai dengan yang diharapkan sehingga sistem dapat digunakan sesuai dengan model yang dirancang.

\section{ANALISA DAN PEMBAHASAN}

Pada saat melakukan penyelesaian laporan stok produk herbal masih mengalami kesulitan karena banyaknya transaksi permintaan dan penjualan yang terjadi setiap harinya. Dimana laporan Stok ini sangat penting karna hasilnya akan menjadi penentuan stok untuk berikutnya, namun dalam pengerjaan laporan ini masih bersifat manual dan belum mempunyai sistem khusus yang dapat menyelesaikan laporan dengan cepat dan hasil perhitungan yang lebih akurat, hal ini menyebabkan keterlambatan dalam penyelesaian laporan dan dapat membuat pihak perusahaan mengalami kerugian.

\subsection{Algoritma Sistem}

Pada permasalahan yang telah diuraikan dapat ditarik kesimpulan beberapa variabel yang digunakan untuk menentukan jumlah stok produk herbal yaitu stok akhir, permintaan dan penjualan serta jumlah pemesanan.

1. Inisialisasi Data Variabel

Berdasarkan data penjualan yang ada, kegiatan pemesanan tidak dilakukan secara rutin setiap hari. Berikut ini merupakan data penjualan selama 3 bulan yaitu dibulan Juni, Juli, Agustus 2018. Data penjualan Produk Herbal perhari dapat dilihat secara detail pada tabel berikut ini.

Tabel 1. Data Penjualan Bulan Januari 2019

\begin{tabular}{ccccc}
\hline Tanggal & Stok awal & Jumlah Penjualan dan permintaan & Stok Akhir & Pemesanan \\
\hline 03-Jan-19 & 610 & 211 & 399 & - \\
04-Jan-19 & 399 & 244 & 155 & 500 \\
05-Jan-19 & 655 & 201 & 454 & - \\
07-Jan-19 & 454 & 358 & 96 & 850
\end{tabular}


JURNAL MEDIA INFORMATIKA BUDIDARMA, Vol 3, No 4, Oktober 2019

ISSN 2614-5278 (media cetak)

ISSN 2548-8368 (media online)

Hal 313-323 | DOI: 10.30865/mib.v3i4.1354

\begin{tabular}{llccc} 
08-Jan-19 & 946 & 218 & 728 & - \\
09-Jan-19 & 728 & 258 & 470 & 400 \\
10-Jan-19 & 870 & 488 & 382 & 500 \\
11-Jan-19 & 882 & 249 & 633 & - \\
12-Jan-19 & 633 & 131 & 502 & 300 \\
14-Jan-19 & 802 & 388 & 414 & - \\
15-Jan-19 & 414 & 207 & 207 & 650 \\
16-Jan-19 & 857 & 410 & 447 & - \\
17-Jan-19 & 447 & 245 & 202 & 700 \\
18-Jan-19 & 902 & 369 & 533 & - \\
19-Jan-19 & 533 & 267 & 266 & 600 \\
21-Jan-19 & 866 & 188 & 678 & - \\
22-Jan-19 & 678 & 256 & 422 & - \\
23-Jan-19 & 422 & 266 & 156 & 700 \\
24-Jan-19 & 856 & 402 & 454 & - \\
25-Jan-19 & 454 & 307 & 147 & 850 \\
26-Jan-19 & 997 & 310 & 687 & - \\
28-Jan-19 & 687 & 625 & 62 & 900 \\
29-Jan-19 & 962 & 297 & 665 & - \\
30-Jan-19 & 665 & 331 & 334 & 650 \\
31-Jan-19 & 984 & 220 & 764 & - \\
\hline
\end{tabular}

Tabel 2. Data Penjualan Bulan Februari 2019

\begin{tabular}{ccccc}
\hline Tanggal & Stok awal & Jumlah Penjualan dan permintaan & Stok Akhir & Pemesanan \\
\hline 01-Feb-19 & 764 & 228 & 536 & - \\
02-Feb-19 & 536 & 101 & 435 & - \\
04-Feb-19 & 435 & 339 & 96 & 800 \\
06-Feb-19 & 896 & 822 & 74 & 1.000 \\
07-Feb-19 & 1.074 & 454 & 620 & - \\
08-Feb-19 & 620 & 198 & 422 & - \\
09-Feb-19 & 422 & 103 & 319 & 500 \\
11-Feb-19 & 819 & 336 & 483 & - \\
12-Feb-19 & 483 & 415 & 68 & 750 \\
13-Feb-19 & 818 & 193 & 625 & - \\
14-Feb-19 & 625 & 165 & 460 & - \\
15-Feb-19 & 460 & 220 & 240 & 500 \\
16-Feb-19 & 740 & 211 & 529 & - \\
18-Feb-19 & 529 & 265 & 264 & 500 \\
19-Feb-19 & 764 & 415 & 349 & - \\
20-Feb-19 & 349 & 308 & 41 & 1.100 \\
$21-F e b-19$ & 1.141 & 299 & 842 & - \\
22-Feb-19 & 842 & 180 & 662 & - \\
23-Feb-19 & 662 & 218 & 444 & - \\
25-Feb-19 & 444 & 310 & 134 & 600 \\
26-Feb-19 & 734 & 154 & 580 & - \\
27-Feb-19 & 580 & 206 & 374 & - \\
28-Feb-19 & 374 & 297 & 77 & 600 \\
\hline
\end{tabular}

Tabel 3. Data Penjualan Bulan Maret 2019

\begin{tabular}{ccccc}
\hline Tanggal & Stok awal & Jumlah Penjualan dan permintaan & Stok Akhir & Pemesanan \\
\hline 01-Mar-19 & 677 & 344 & 333 & 250 \\
02-Mar-19 & 583 & 137 & 446 & - \\
04-Mar-19 & 446 & 221 & 225 & 500 \\
05-Mar-19 & 725 & 298 & 427 & - \\
06-Mar-19 & 427 & 186 & 241 & - \\
08-Mar-19 & 241 & 208 & 33 & 800 \\
09-Mar-19 & 833 & 388 & 445 & - \\
11-Mar-19 & 445 & 165 & 280 & - \\
12-Mar-19 & 280 & 131 & 149 & 650 \\
13-Mar-19 & 799 & 108 & 691 & -
\end{tabular}




$\begin{array}{llccc}\text { 14-Mar-19 } & 691 & 202 & 489 & - \\ \text { 15-Mar-19 } & 489 & 388 & 101 & 700 \\ \text { 16-Mar-19 } & 801 & 245 & 556 & - \\ \text { 18-Mar-19 } & 556 & 173 & 383 & - \\ \text { 19-Mar-19 } & 383 & 282 & 101 & 700 \\ \text { 20-Mar-19 } & 801 & 483 & 318 & - \\ \text { 21-Mar-19 } & 318 & 201 & 117 & 800 \\ \text { 22-Mar-19 } & 917 & 266 & 651 & - \\ \text { 23-Mar-19 } & 651 & 305 & 346 & - \\ \text { 25-Mar-19 } & 346 & 306 & 40 & - \\ \text { 26-Mar-19 } & 940 & 210 & 730 & - \\ \text { 27-Mar-19 } & 730 & 198 & 222 & 500 \\ \text { 28-Mar-19 } & 532 & 310 & 352 & - \\ \text { 29-Mar-19 } & 772 & 420 & 132 & 600 \\ \text { 30-Mar-19 } & 352 & 220 & & -\end{array}$

Dari data penjualan di atas, jika diketahui stok akhir = 132 dan penjualan terakhir adalah 220, berapa jumlah Produk yang harus di beli untuk hari berikutnya. Dengan Demikian proses perhitungan untuk mengetahui besaran jumlah pemesanan akan diselesaikan dengan metode fuzzymamdani.

2. Pembentukan Himpunan Fuzzy (Fuzzyfikasi)

Tingkat variasi dari stok akhir, penjualan dan permintaan juga pemesanan setiap harinya cukup tinggi, dimana tidak ada 3 bulan berturut-turut memiliki data yang sama. Data dikelompokkan berdasarkan nilai pada setiap variabel sehingga kita dapat mengetahui berapa nilai minimum dan maksimum.

Tabel 4. Penentuan Variabel Sabun Transparan Kolagen

\begin{tabular}{clll}
\hline Fungsi & \multicolumn{1}{c}{ Variabel } & \multicolumn{1}{c}{ Semesta } & \multicolumn{1}{c}{ Kembicaraan } \\
\hline Input & Stok Akhir & {$[33-842]$} & Jumlah Stok Akhir \\
& & & Sabun Kecantikan \\
& & & per tiga bulan (Kolagen) \\
& Penjualan \& Permintaan & {$[101-822]$} & Jumlah Penjualan \& Permintaan \\
& & & Sabun Kecantikan \\
Output & Pemesanan & {$[250-1.100]$} & per tiga bulan (Kolagen) \\
& & & Jumlah Pemesanan \\
& & & Sabun Kecantikan \\
\hline
\end{tabular}

a. Sabun Transparan Kolagen

1). Variabel stok akhir terdiri dari sedikit, sedang dan banyak.

\section{Variabel Stok Akhir}

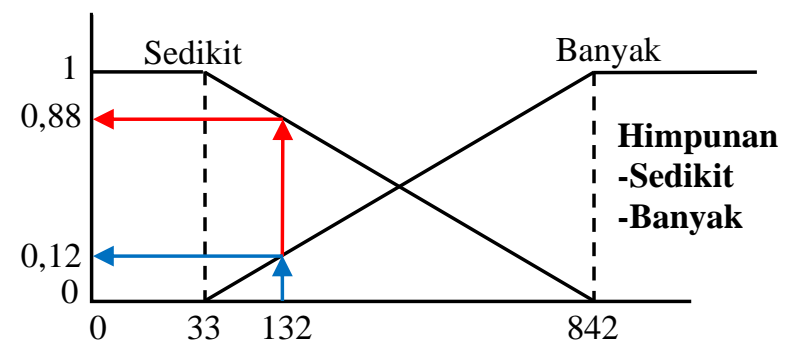

Gambar 1. Daerah hasil variabel stok akhir

$$
\begin{aligned}
& \text { Stok akhir } \mu_{\text {sedikit }}= \begin{cases}\frac{842-x}{842-33} \quad 33 \leq x \leq 842 & x 3 \\
& x \geq 842\end{cases} \\
& \text { Stokakhir } \mu_{\text {sedikit }}=\frac{842-132}{842-33}=\frac{710}{890}=0,88
\end{aligned}
$$


Stok akhir $\mu_{\text {banyak }}= \begin{cases} & x<33 \\ \frac{x-33}{842-33} \quad 33 \leq x \leq 842 & x \geq 842\end{cases}$

$$
\text { Stokakhir } \mu_{\text {banyak }}=\frac{132-33}{842-33}=\frac{99}{809}=0,12
$$

2). Variabel penjualan terdiri dari naik dan turun.

$$
\begin{aligned}
& \text { Variabel Penjualan \& Permintaan } \\
& \text { Surun } \\
& \text { Penjualan } \mu_{\text {turun }}= \begin{cases}\frac{822-y}{822-101} 101 \leq y \leq 822 & y<101 \\
& y \geq 822\end{cases} \\
& \text { Penjualan } \mu_{\text {turun }}=\frac{822-220}{822-101}=\frac{602}{721}=0,83 \\
& \text { Penjualan } \mu_{\text {naik }}= \begin{cases}\frac{y-101}{822-101} 101 \leq y \leq 822 & y<101 \\
& y \geq 822\end{cases} \\
& \text { Penjualan } \mu_{\text {naik }}=\frac{220-101}{822-101}=\frac{119}{721}=0,17
\end{aligned}
$$

3). Variabel pemesanan terdiri dari berkurang dan bertambah

\section{Variabel Pemesanan}

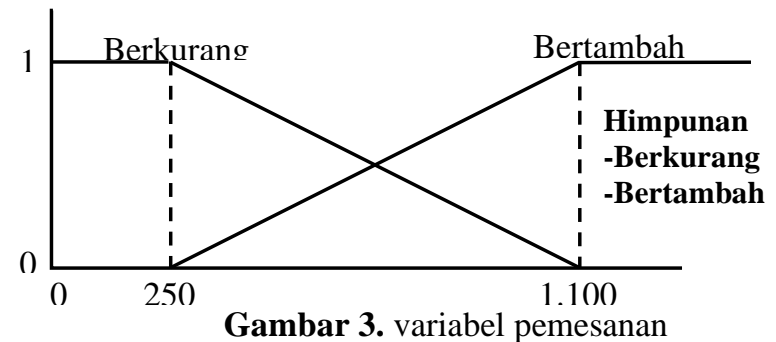

$$
\begin{gathered}
\text { Pemesanan } \mu_{\text {berkurang }}= \begin{cases}\frac{1.100-z}{1.100-250} 250 \leq z \leq 1.100 & z<250 \\
\text { Pemesanan } \mu_{\text {bertambah }}= \begin{cases}z \geq 1.100 \\
\frac{z-250}{1.100-250} 250 \leq z \leq 1.100 & z<250\end{cases} \\
z \geq 1.100\end{cases}
\end{gathered}
$$


3. Penetapan Basis Aturan

Untuk mencari nilai z disetiap aturan menggunakan fungsi $M I N$ pada aplikasi fungsi implikasinya:

a. [R1] JIKA penjualan dan permintaan TURUN dan stok akhir BANYAK, MAKA pemesanan BERKURANG

[R1] JIKA penjualan dan permintaan TURUN $=0.83$ dan stok akhir BANYAK $=0.12$, MAKA pemesanan BERKURANG, $\min =\{0.83,0.12\}=0.12$

b. [R2] JIKA penjualan dan permintaan TURUN dan stok akhir SEDIKIT, MAKA pemesanan BERKURANG.

[R2] JIKA penjualan dan permintaan TURUN $=0.83$ dan stok akhir SEDIKIT $=0.88$, MAKA pemesanan BERKURANG, $\min =\{0.83,0.88\}=0.83$

c. [R3] JIKA penjualan dan permintaan NAIK dan stok akhir BANYAK, MAKA pemesanan BERTAMBAH.

[R3] JIKA penjualan dan permintaan NAIK $=0.17$ dan stok akhir BANYAK $=0.12$, MAKA pemesanan BERTAMBAH, $\min =\{0.17,0.12\}=0.12$

d. [R4] JIKA penjualan dan permintaan NAIK dan stok akhir SEDIKIT, MAKA pemesanan BERTAMBAH.

[R4] JIKA penjualan dan permintaan NAIK $=0.17$ dan stok akhir SEDIKIT $=0.88$, MAKA pemesanan BERTAMBAH, $\min =\{0.17,0.88\}=0.17$

4. Proses Mesin Inferensi

Metode yang digunakan untuk melakukan komposisi antar semua aturan adalah metode MAX.

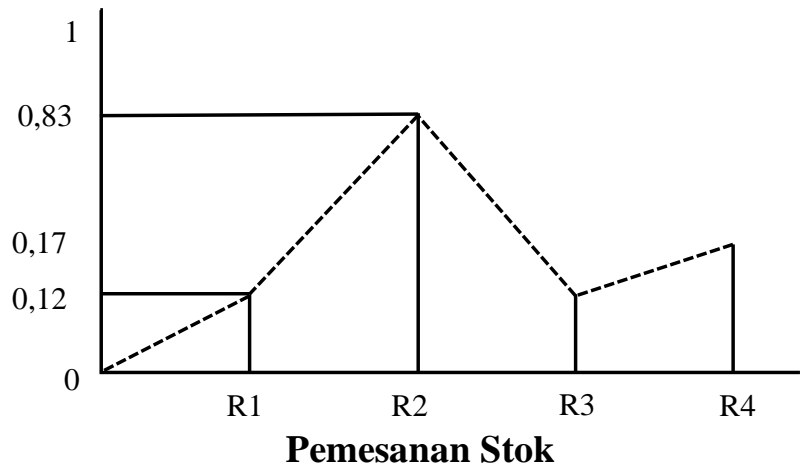

Gambar 4. Daerah Hasil Komposisi

$$
\begin{aligned}
& {[R 1]=\frac{\text { maxpemesanan }-z_{1}}{\max -\min }} \\
& 0,12=\frac{1.100-z_{1}}{1.100-250} \\
& 0,12=\frac{1.100-z_{1}}{850} \\
& 0,12 \times 850=1.100-Z_{1} \\
& Z_{1}=1.100-102 \\
& Z_{1}=998 \\
& {[R 2]=\frac{\text { maxpemesanan }-z_{2}}{\max -\min }} \\
& 0,83=\frac{1 \cdot 100-z_{2}}{1 \cdot 100-250} \\
& 0,83=\frac{1.100-z_{2}}{850} \\
& 0,83 \times 850=1.100-Z_{2} \\
& Z_{2}=1.100-705.5 \\
& Z_{2}=394.5 \\
& {[R 3]=\frac{z_{3}-\text { minpemesanan }}{\max -\min }} \\
& 0,12=\frac{z_{3}-250}{1.100-250} \\
& 0,12=\frac{z_{3}-250}{850}
\end{aligned}
$$




$$
\begin{aligned}
& 0,12 \times 850=Z_{3}-250 \\
& Z_{3}=250+102 \\
& Z_{3}=352 \\
& {[R 4]=\frac{Z_{4}-\text { minpemesanan }}{\text { max }- \text { min }}} \\
& 0,17=\frac{Z_{4}-250}{1.100-250} \\
& 0,17=\frac{Z_{4}-250}{850} \\
& 0,17 \times 850=Z_{4}-250 \\
& Z_{4}=250+144.5 \\
& Z 4=394.5
\end{aligned}
$$

5. Hasil Akhir (Defuzzyfikasi)

Penegasan atau defuzzy dikerjakan menggunakan metode centroid.

$$
\begin{aligned}
& Z^{*}=\frac{\sum_{j=1}^{n} Z_{j} \mu\left(Z_{j}\right)}{\sum_{j=1}^{n} \mu\left(Z_{j}\right)} \\
& Z=\frac{\left(Z_{1} *[R 1]\right)+\left(Z_{2} *[R 2]\right)+\left(Z_{3} *[R 3]\right)+\left(Z_{4} *[R 4]\right)}{[R 1]+[R 2]+[R 3]+[R 4]} \\
& Z=\frac{(998 * 0,12)+(394,5 * 0,83)+(352 * 0,12)+(394,5 * 0,17)}{0,12+0,83+0,12+0,17} \\
& Z=\frac{119,76+327,43+42,24+67,06}{1,24} \\
& Z=\frac{556.49}{1,24} \\
& Z=448,78(449)
\end{aligned}
$$

Berdasarkan hasil perhitungan data transaksi selama 3 (tiga) bulan dengan menggunakan metode Fuzzy Mamdani, diketahui bahwa jumlah pemesanan stok yang harus diadakan pada pemesanan berikutnya agar tidak terjadi kekurangan adalah 449 Pcs.

\section{IMPLEMENTASI}

Tahap implementasi sistem merupakan lanjutan dari tahap perancangan, yang sudah dilaksanakan sebelumnya dan pengujian dilakukan untuk melihat apakah setiap proses yang ada berjalan dengan baik dan output yang dihasilkan sudah sesuai dengan yang diharapkan.

1. Form Login

Sebelum masuk ke menu utama, maka user harus melakukan login terlebih dahulu, adapaun tampilan form login sebgai berikut:

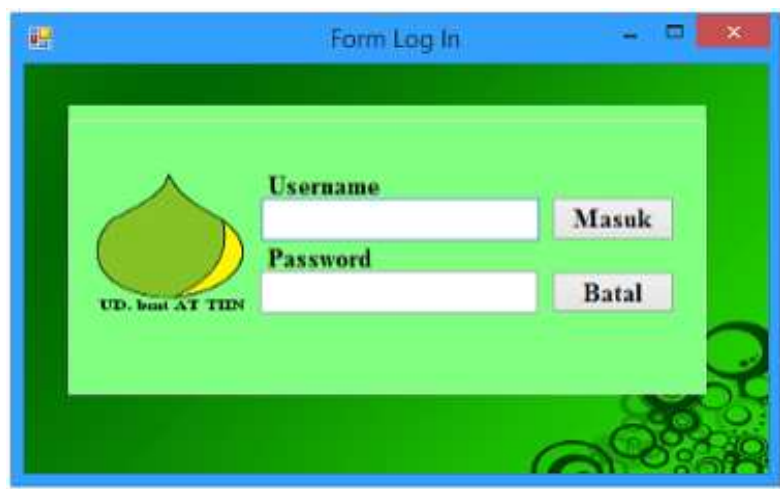

Gambar 5. Tampilan Form Login

2. Tampilan Input Data Pemasanan

Tampilan form input data pendapatan dapat dilihat pada gambar 6 dibawah ini: 
JURNAL MEDIA INFORMATIKA BUDIDARMA, Vol 3, No 4, Oktober 2019

ISSN 2614-5278 (media cetak)

ISSN 2548-8368 (media online)

Hal 313-323 | DOI: 10.30865/mib.v3i4.1354

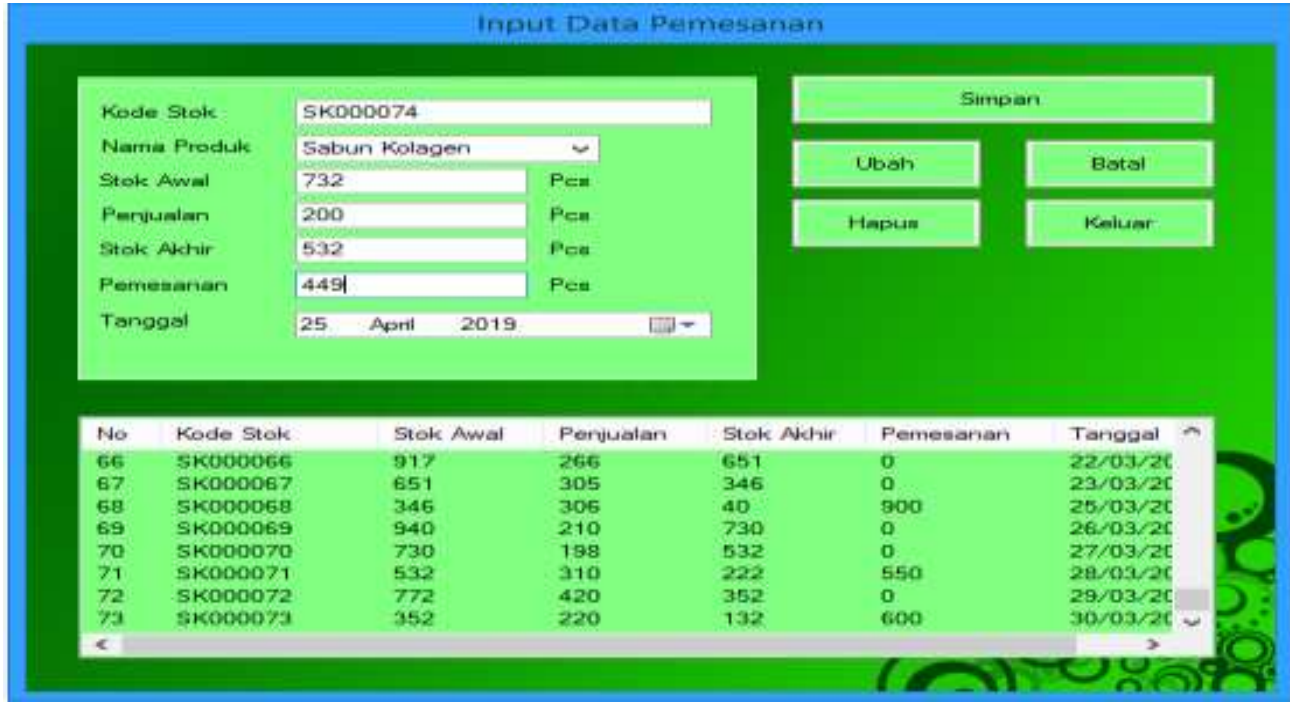

Gambar 6. Tampilan form Input Data

3. Form Proes

Tampilan form Pilihan proses dapat dilihat pada gambar 6 dibawah ini:

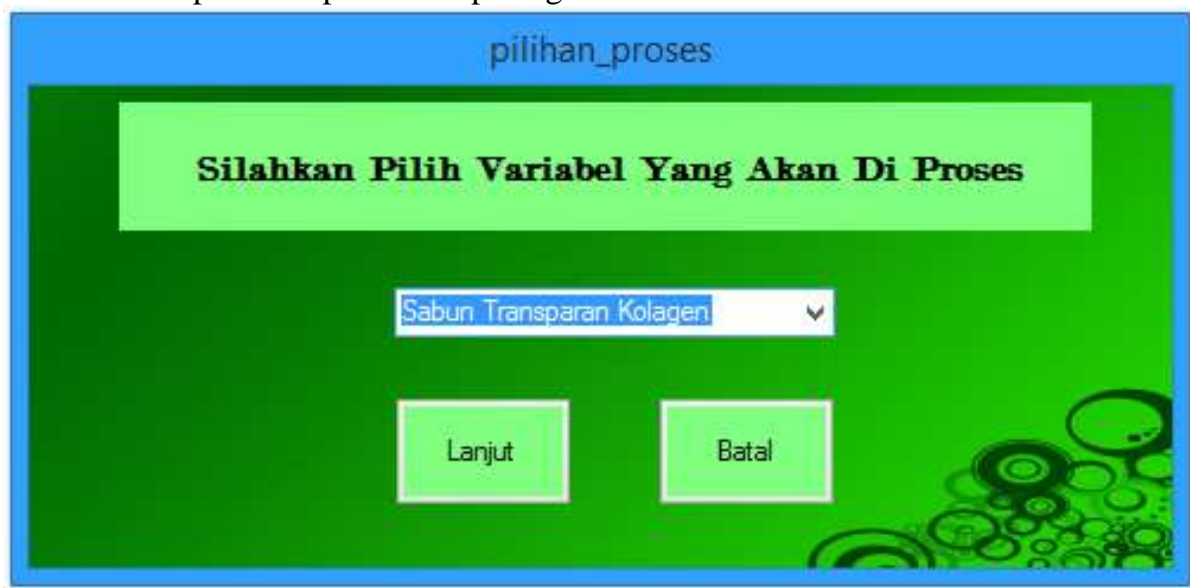

Gambar 7. Tampilan Form Pilihan Proses

Tampilan form proses Fuzzy Mamdani dapat dilihat pada gambar 7 dibawah ini :

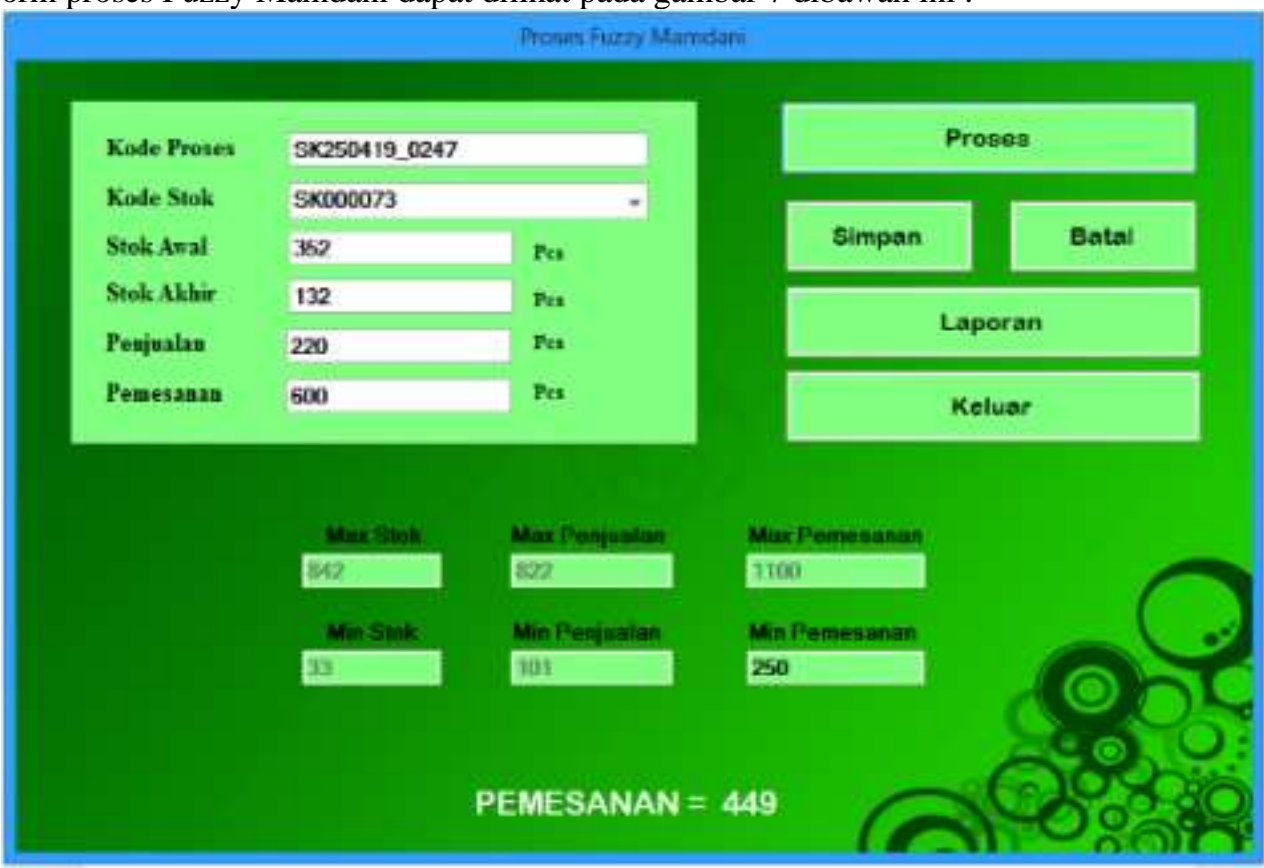

Gambar 8. Tampilan form Fuzzy Mamdan

Asyahri Hadi Nasyuha | http://ejurnal.stmik-budidarma.ac.id/index.php/mib | Page | 321 
4. Form Laporan Hasil Prediksi Produk

Tampilan awal Hasil Penjualan dapat dilihat pada gambar dibawah ini:

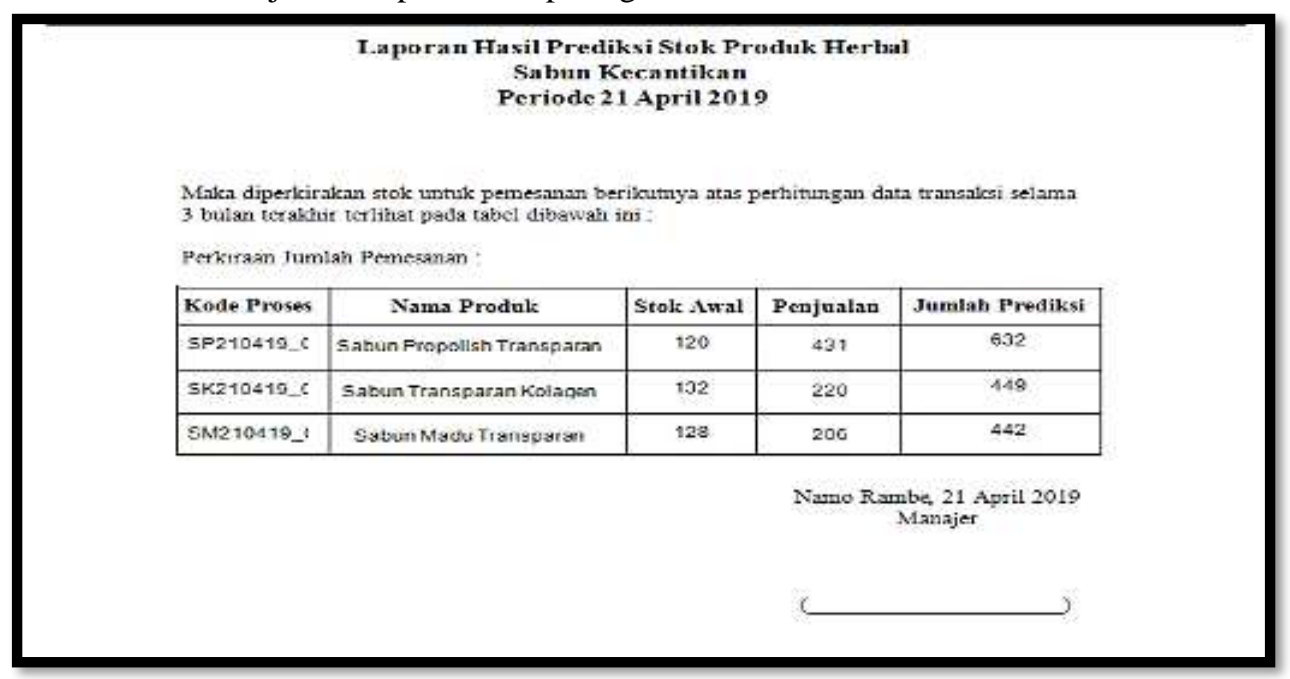

Gambar 9. Tampilan form laporan

Kelebihan dan Kelemahan Sistem setelah dilakukan pengujian terhadap aplikasi ini Sistem Pendukung Keputusan untuk Menentukan Stok Produk Herbal berdasarkan Permintaan dan Penjualan Menggunakan Medote Fuzzy Mamdani mungkin terdapat kelebihan maupun kekurangannya sebagai berikut:

Kelebihan Sistem

Adapun kelebihan dari sistem yang dibangun adalah sebagai berikut :

1. Aplikasi pendukung keputusan ini dapat menambah jumlah pemesanan dengan kebutuhan perusahaan.

2. Hasil proses pada Sistem Pendukung Keputusan untuk Menentukan Stok Produk Herbal ini dilengkapi dengan perhitungan menggunakan metode Fuzzy Mamdani sehingga hasil keputusan menjadi lebih cukup tepat dan akurat.

3. Sistem yang dirancang dapat diubah sesuai dengan perkembangan tambahan jenis permasalahan lainnya.

Kelemahan Sistem

Adapun kelemahan dari sistem yang dibangun adalah sebagai berikut :

1. Aplikasi pendukung keputusan pada penelitian ini dibangun hanya untuk memprediksi jumlah Produk herbal jenis Sabun Kecantikan.

2. Sistem hanya dapat menganalisa berdasarkan data-data yang sudah ditentukan oleh pengguna program, selebihnya tergantung kepada kebijakan pemimpin perusahaan.

3. Tampilan aplikasi masih sederhana dan butuh masukan agar lebih bagus.

4. Aplikasi yang dibangun masih perlu pengembangan-pengembangan.

\section{KESIMPULAN}

Dari hasil implementasi dan hasil pengujian yang diperoleh dari perancangan aplikasi sistem pendukung keputusan untuk menentukan stok produk herbal berdasarkan permintaan dan penjualan menggunakan metode fuzzy mamdani, maka dapat diambil kesimpulan sebagai berikut:

1. Sistem pendukung keputusan ini dapat membantu dalam mengerjakan laporan secara lebih efektif dan efesien dengan menggunakan data-data yang telah ditentukan.

2. Sistem pendukung keputusan ini dapat diterapkan dengan metode Fuzzy Mamdani dalam menentukan jumlah Stok Produk Herbal dengan cara menentukan nilai variabel untuk masing-masing kriteria.

3. Sistem pendukung keputusan yang dibangun ini dirancang khusus untuk menentukan stok produk herbal berdasarkan permintaan dan penjualan menggunakan metode fuzzy mamdani.

4. Aplikasi sistem pendukung keputusan yang dibangun dapat mengurangi terjadinya keterlambatan dalam kegiatan pengerjaan laporan dan proses pemesanan.

\section{REFERENCES}

[1] Abrori, M, Prihamayu. 2015. Aplikasi Logika Fuzzy Metode Mamdani dalam Pengambilan keputusan Penentuan Jumlah Produksi. Jurnal Kaunia. XI (2):95

[2] Nasyuha, A.H., 2019. Sistem Pendukung Keputusan Menentukan Pemberian Pinjaman Modal dengan Metode Multi Attribute Utility Theory. JURNAL MEDIA INFORMATIKA BUDIDARMA, 3(2), pp.117-125.

[3] Anthony, Tanaamah \& Wijaya. 2017. Analisis Dan Perancangan Sistem Informasi Penjualan Berdasarkan Stok Gudang Berbasis Client Server. Jurnal Teknologi Informasi dan Ilmu Komputer (JTIIK). 4(2):138-139 
JURNAL MEDIA INFORMATIKA BUDIDARMA, Vol 3, No 4, Oktober 2019

ISSN 2614-5278 (media cetak)

ISSN 2548-8368 (media online)

Hal 313-323 | DOI: 10.30865/mib.v3i4.1354

[4] Cendra Wadisman. 2018. Perancangan Aplikasi Pengolahan Data Logistik pada Kantor Cabang BRI Solok. Jurnal INTECOMS $1(2): 142$

[5] Ester Salangka. 2013. Penerapan Akuntansi Persediaan untuk Perencanaan dan Pengendalian LPG pada PT. Emigas Sejahtera Minahasa. Jurnal EMBA. 1(3):1121-1122

[6] Herson Anwar. 2014. Proses Pengambilan Keputusan untuk Mengembangkan Mutu Madrasah. Jurnal Pendidikan Islam. 8(1):49

[7] Jubile Enterprise. 2017. Otodidak Visual Basic. Jakarta: PT Elex Media Komputindo

[8] Kusumadewi, S, Purnomo. 2013. APLIKASI LOGIKA FUZZY Untuk Sistem Pendukung Keputusan. Yogyakarta: Graha Ilmu

[9] Murni, M, Bosker. 2018. Buku Ajar Sistem Pendukung Keputusan Penilaian Hasil Belajar Dengan Metode Topsis. Medan: CV. Rudang Mayang

[10] Nofriansyah, D, Defit. 2017. MULTI CRITERIA DECISION MAKING(MCDM) Pada Sistem Pendukung Keputusan. Yogyakarta: Deepublish

[11] Pontoh, Palar \& Mauna. 2016. Permintaan dan Penawaran Beras di Indonesia (Pada Tahun 2003 - Tahun 2013). Jurnal Berkala Ilmiah Efisiensi. 16 (04):835-836

[12] Putra, Pandawani \& Citra. 2015. Peningkatan Kualitas Produk Herbal Dan Kosmetika Natural Bali. Jurnal Bakti Saraswati. 04(02):92 